\title{
Buckling Analysis of Bedded Rock Slope Subject to Seismic Force - a Case Study in Karakoram Highway, Pakistan
}

\author{
Liping Liao ${ }^{1}$, Yingyan Zhu ${ }^{2 *}$, Zhiquan Yang ${ }^{3}$, D.H. Steve Zou ${ }^{4}$, Waseem Muhammad ${ }^{5}$, Jiding Chen ${ }^{6}$, \\ Yun Wang ${ }^{6}$, Chenyin $\mathrm{Ye}^{7}$ \\ ${ }^{1}$ College of Civil Eng. and Architecture, Guangxi University, Nanning, China \\ ${ }^{2}$ Key Laboratory of Mountain Surface Process and Hazards, Chinese Academy of Sciences, Chengdu, \\ China; Institute of Mountain Hazards and Environment, Chinese Academy of Sciences, Chengdu, China \\ ${ }^{3}$ Faculty of Land Resource Eng., Kunming University of Science and Technology, Kunming, China \\ ${ }^{4}$ Dalhousie University, Halifax, Nova Scotia, Canada \\ ${ }^{5}$ University of Peshawar, Peshawar, Pakistan \\ ${ }^{6}$ China Academy of Transportation Sciences, Beijing, China \\ ${ }^{7}$ China Road and Bridge Corporation, Beijing, China
}

\begin{abstract}
Buckling deformation of bedded rock slope is common in the northern region of the Hunza river along China-Pakistan International Karakoram Highway $(\mathrm{KKH})$, Pakistan. In order to analyze the failure mechanism, an explicit general failure formula is established to depict the flexural buckling of plane slopes subject to seismic force based on the theory of column stability and stress equilibrium. A comparison is made between the flexural buckling subject to seismic force and the buckling without seismic force. The rock slope of $\mathrm{K} 745$ at $\mathrm{KKH}$ is analyzed to evaluate the effects of three key parameters - seismic force (horizontal acceleration), slope inclination angle and friction angle.
\end{abstract}

Keywords: China-Pakistan International Karakoram Highway, seismic force, buckling failure, column stability, bedded rock slope

\section{Introduction}

The China-Pakistan International Karakoram Highway $(\mathrm{KKH})$ has been constructed through three high mountain terrains - the Himalayas, Karakoram and Pamir, and two earthquake belts Karakorum Pamirs earthquake belt and Himalayas earthquake belt. The route of the highway is characterized by highly fractured rocks, extensive areas of debris accumulation and high rates of geomorphological activities and has encountered many extreme geohazards related to rock slopes, landslides and buckling failure. They have posed significant potential threats to the construction and maintenance of the KKH. This paper will concentrate on analysis of buckling failure in this area.

From the mechanism point of view, buckling failures are classified as flexural buckling of plane slopes, three hinge buckling of plane slopes and three hinge buckling of curved slopes (Goodman 1976). Flexural buckling failures may occur if certain geometrical conditions exist, as follows: 1) presence of stratified rocks with a columnar or slab shaped structure (Froldi and Lunardi 1995) and the cleavage is significant and regular, 2) the plane of the main discontinuities must parallel to the slope face, 3 ) both the length and the width of the rock

*Corresponding Author: Yingyan Zhu, email: yingyan.z@dal.ca, Tel: +86 13880122428

(C) Copyright 2016 Canamaple Academia Services, http://press.camdemia.ca

DOI: 10.15273/ijge.2016.01.003 
slab are far larger than its thickness, and 4) the inclination angle of the main discontinuities or the bedding planes must be larger than the friction angle of those discontinuities. Buckling occurring near the slope toe can be considered to be a debonding block (formation above the sliding plane in the dip direction) (Shou and Wang 2003).

On the basis of field observations, the slopes of K745 and K765 in the northern region of the Hunza river along $\mathrm{KKH}$ satisfy the above conditions of flexural buckling. This buckling is regarded as a plane strain problem where the slab thickness is very small relative to its length. Buckling force is induced by rock's own weight and external forces, such as water pressure or stress concentrations on the plane of the plates. Figures 1 and 2 show rock slopes of K745 and K765 located in the northern region of the Hunza River. The lithology is generally slate (Zhu et al 2012 ), the inclination angle is about $57^{\circ} \sim 80^{\circ}$ and the slab thickness of rock slope is $0.10 \sim 0.82 \mathrm{~m}$.

A number of studies have been conducted to understand the buckling failure mechanism. Kutter (1974) described the buckling occurred in an open pit coal mine in England. Hoek and Bray (1981) pointed out it was easier to fail by buckling when the friction angle was small. Corbyn (1978) analyzed the stability of rock slopes subject to tensile stress in the outer fiber of a curved slab. Based on research by Hoek and Bray (1981) and Corbyn (1978), Cavers (1981) presented Euler's expression for the maximum load per unit slope width before buckling occurred, established the conditions for buckling failure and analyzed the three modes of buckling failure in sedimentary rock layers. Furthermore, he presented three formulas for these three modes of buckling failure. In order to apply Euler's concepts to slopes, he assumed that only a certain portion of rock layer located in the slope toe region buckles and the rest of the rock layer simply provided an axial load to the buckling portion of the rock layer. On the basis of base friction model tests, he gave a range of values for the ratio of buckling slab length to total slab length between 0.36 and 0.46 . He further assumed a ratio of 0.5 for use, which is slightly conservative compared to the results of base friction models (Goodman 1976).

Pant and Adhikary (1999) used the equivalent continuum (implicit joint) model based on Cosserat continuum theory and explicit joint

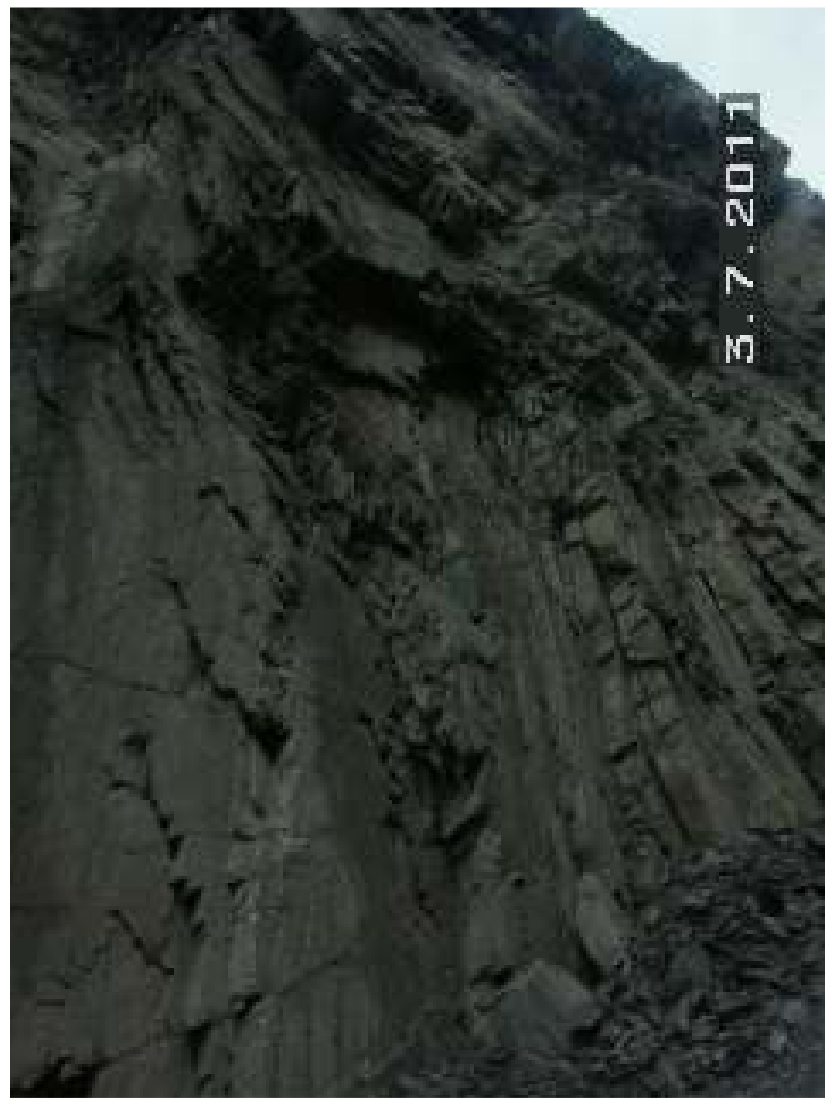

Fig. 1 Buckling failure of rock bedded slope in K745

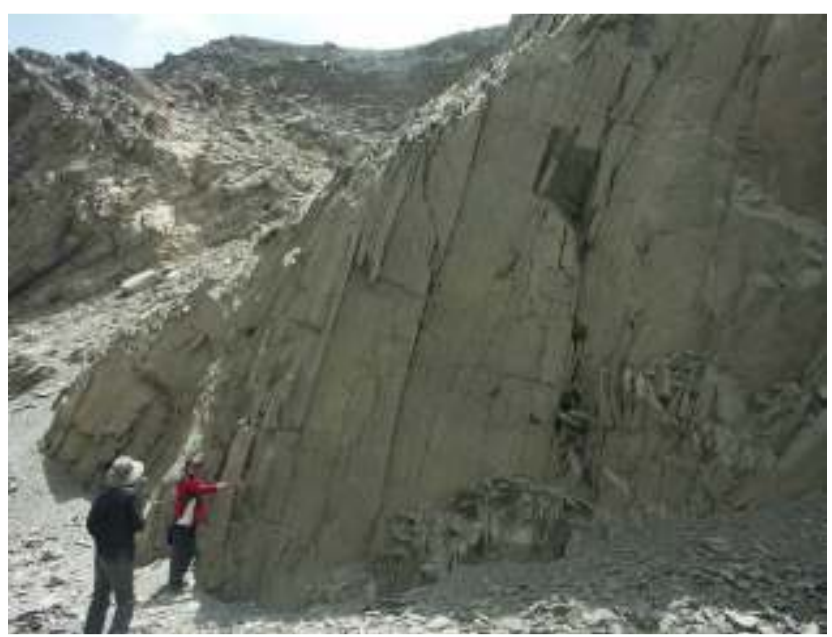

Fig. 2 Buckling failure of rock bedded slope in K765

model (FLAC) to study the mechanism of buckling failure of foliated rock slopes. Adhikary et al (2001) rearranged Caver's expression for a nondimensional term named the critical force for flexural buckling, then presented a comprehensive 
numerical model that was valid for large deformations and applied this model for analysis of flexural buckling phenomena in foliated rock masses. Liu and Zhou (2002) assumed bedded rock slopes as elastic boards and analyzed the failure of bedded rock slopes. Shou and Wang (2003) considered the seismic force and modified the Caver's formula. They found that the length of the debonded sliding block subject to seismic force was very close to the slope length in reality. This finding is strongly compatible with the need for estimation of seismic effect on flexural buckling failure. Li et al (2007) attained the safety coefficient. Li and Zhang (2007) used the pseudostatic method to analyze the stability of bedded rock slopes subject to seismic force. Pereira and Lana (2013) used finite element software named Phase $^{2}$ of Rocsceinece Inc (2008) (Canada) to evaluate the buckling failure mechanism through stress-strain analysis.

In order to understand the effects of the seismic force on rock slopes, this paper applies the pseudostatic method to analyze the buckling of bedded rock slopes subject to seismic force. Based on the general explicit formula for flexural buckling failure, a comparison is made between flexural buckling of plane slope under no seismic force (case 1) and flexural buckling of the same slope subject to seismic force (case 2). For the slope of $\mathrm{K} 745$, the effects of three important parameters on flexural buckling, seismic force (horizontal peak acceleration), slope inclination angle $\alpha$ and friction angle $\Phi_{j}$, are discussed.

\section{Flexural Buckling Subject to Seismic Forces}

Similar to Cavers (1981), the mechanical model of bedded rock slope buckling is simplified as a beam stability problem in this study and its deflection curve can be approximated by a linear function (Chajes 1974). This model satisfies with the classical buckling theory (Euler Method) with the assumptions that the column is straight and elastic and it obeys Hoek's Law, as illustrated in Fig. 3. According to the theory of beam stability, an analytical solution is derived for the buckling slope failure taking into account the effect of earthquake expressed as follows.
The critical load per unit width, $P_{c r} / b$, before buckling occurs can be calculated as follows (see Fig. 3).

$$
\frac{P_{c r}}{b}=\frac{K \pi^{2} E I}{b l_{b}^{2}}
$$

where $b$ is unit width, $E$ is Young's modulus, $K$ is a constant describing end conditions, $I$ is the moment of inertia and $l_{b}$ is the length of slope subject to buckle, for a rectangular column.

I can be calculated by

$$
I=\frac{b d^{3}}{12}
$$

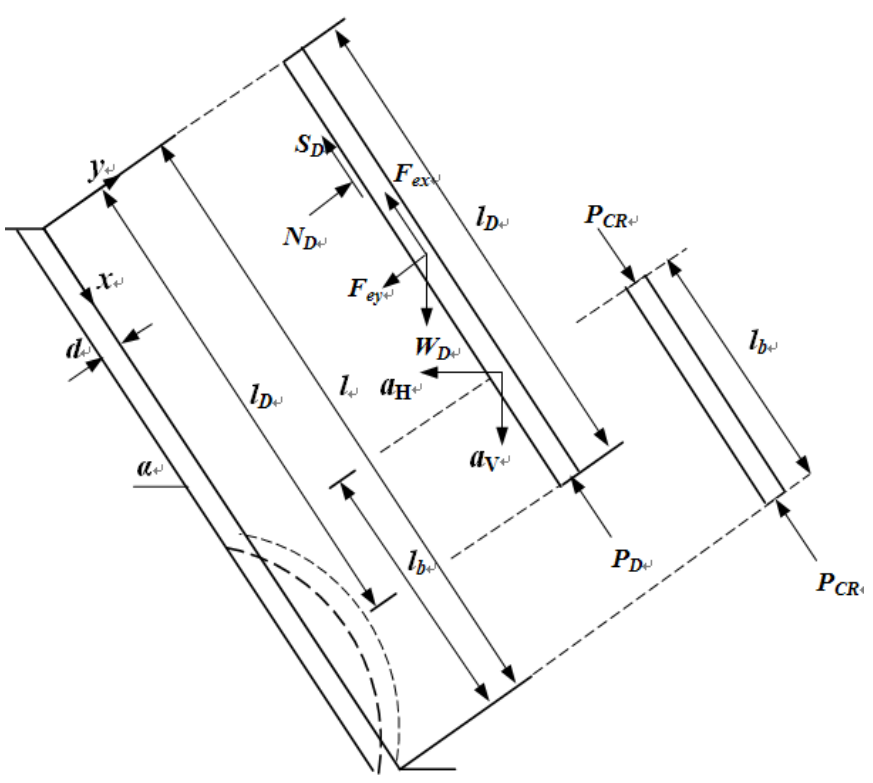

Fig. 3 Simplified model of flexural buckling on plane slope subject to seismic force

In Eqn. (2), $d$ is slab thickness. For a rock slab which contains cross joints perpendicular to the bedding plane, the end of the rock slope should be hinged and it seems reasonable to assume $K=1$ (Cavers 1981).

The seismic force is resolved into two steady inertial components, $F_{e x}$ in $x$ direction and $F_{e y}$ in $y$ direction, respectively, acting on the center of gravity of the plane slope in the Goodman model (Fig. 3).

If the horizontal peak acceleration $a_{\mathrm{H}}$ and the vertical peak acceleration $a_{\mathrm{V}}$ are determined, $F_{e x}$ and $F_{e y}$ can be calculated as follows, 


$$
\begin{aligned}
& F_{e x}=l_{D} \gamma d\left(a_{H} \cos \alpha-a_{V} \sin \alpha\right) \\
& F_{e y}=l_{D} \gamma d\left(a_{H} \sin \alpha+a_{V} \cos \alpha\right)
\end{aligned}
$$

where $l_{D}$ is the length of the driving segment, $\gamma$ is the unit weight and $\alpha$ is the inclination angle of the slope.

To account for the weight of the rock slab, the portion of the slab above the hinge point will be added to the driving force that is acting on the slope. According to force equilibrium in the $x$ direction, the driving force $P_{D}$ is calculated by

$\frac{P_{D}}{b}=\left[W_{D} \sin \alpha-\left(W_{D} \cos \alpha+F_{e y}\right) \tan \phi_{j}-F_{e x}-l_{D} C\right]$

where $\Phi_{j}$ is friction angle, $c$ is cohesion and $W_{D}$ is the weight of the block and equals to $l_{D} \gamma d$. The driving force should be positive when

$$
W_{D} \sin \alpha-\left(W_{D} \cos \alpha+F_{e y}\right) \tan \phi_{j}-F_{e x}-l_{D} C \geq 0 .
$$

Consider a ratio $l_{b} / l=0.5$ as suggested by Cavers (1981) and let Eqn. (1) = Eqn. (4), the total slope length $l$ at the critical condition of buckling is calculated as follows,

$$
l^{3}=\frac{\pi^{2} E d^{3}}{2.25\left[\begin{array}{l}
\gamma d \sin \alpha-\gamma d\left(\cos \alpha+a_{H} \sin \alpha+a_{V} \cos \alpha\right) \operatorname{tg} \phi_{j} \\
-\gamma d\left(a_{H} \cos \alpha-a_{V} \sin \alpha\right)-c
\end{array}\right]}
$$

where the friction force should be positive when $\cos \alpha+a_{\mathrm{H}} \sin \alpha+a_{\mathrm{V}} \cos \alpha \geq 0$. If $a_{\mathrm{V}}=0$ and $a_{\mathrm{H}}$ is negative (pointing out of slope), $\alpha \geq$ arccotangent $\left(-a_{\mathrm{H}}\right)$. Units used in Eqn. (5) are as follows: $E$ in $\mathrm{GPa}, a_{\mathrm{H}}$ and $a_{\mathrm{V}}$ in $\mathrm{m}^{2} / \mathrm{s}, l$ and $d$ in $\mathrm{m}, \gamma$ in $\mathrm{kN} / \mathrm{m}^{3}$, $\Phi_{j}$ and $\alpha$ in degree, $c$ in $\mathrm{MPa}$.

\section{Case study}

\subsection{Effects of seismic force}

A comparison is carried out below between flexural buckling of plane slopes subject to seismic force (case 2) and without seismic force (case 1). The properties of the rock mass and geometrical parameters are obtained from Cavers (1981) and are shown in Table 1 . When $\alpha=60^{\circ}$ and $a_{\mathrm{V}}=0$, if $\cos \alpha+a_{\mathrm{H}} \sin \alpha+a_{\mathrm{V}} \cos \alpha \geq 0, a_{\mathrm{H}} \geq-0.058$ g. Thus $a_{\mathrm{H}}= \pm 0.038 \mathrm{~g}$ is considered in case 2 .

In case 1, the total slope length $l$ in the critical condition of buckling is calculated by the following formula from Cavers (1981). The relationship between $l$ and $d$ is illustrated in Fig. 4 .

In case 2 , the total slope length $l$ in the critical condition of buckling is obtained by Eqn. (5).

The relations between the total length $l$ and the slab thickness $d$ are shown in Fig. 5 (a) for the condition where the horizontal seismic acceleration is in the same direction $\left(a_{\mathrm{H}}\right.$ is positive, pointing into the slope, as shown in Fig. 3. Fig. 5 (b) presents the results when the seismic acceleration is in the opposite direction $\left(a_{\mathrm{H}}\right.$ is negative, pointing out the slope).

$$
l^{3}=\frac{\pi^{2} E d^{3}}{2.25\left(\gamma d \sin \alpha-r d \cos \alpha \operatorname{tg} \phi_{j}-c\right)}
$$

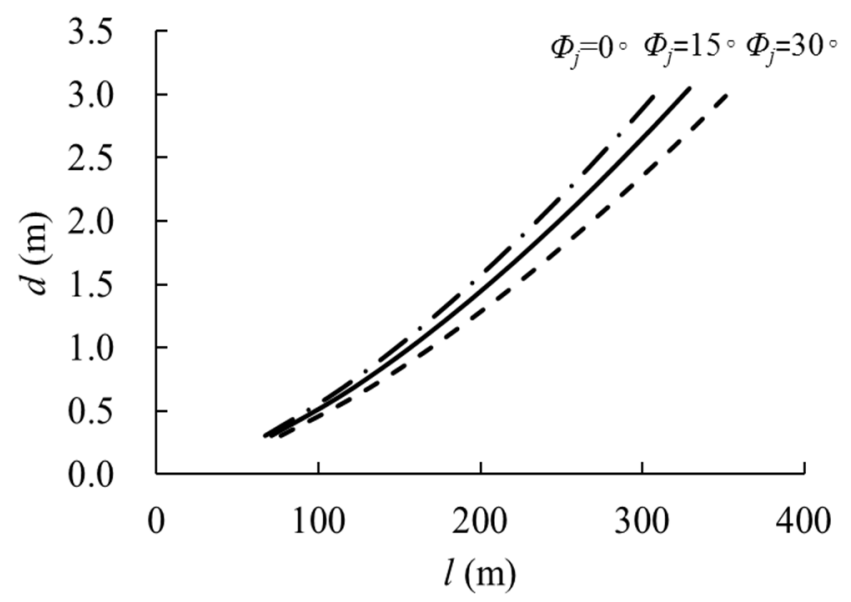

Fig. $4 l$ varies with $d$ (Cavers 1981)

Table 1 The properties of rock mass and geometrical parameters (Cavers 1981)

\begin{tabular}{cccccc}
\hline$\gamma\left(\mathrm{kN} / \mathrm{m}^{3}\right)$ & $c(\mathrm{MPa})$ & $E(\mathrm{GPa})$ & $\alpha\left(^{\circ}\right)$ & $d(\mathrm{~m})$ & $\Phi_{j}\left({ }^{\mathrm{o}}\right)$ \\
\hline \multirow{2}{*}{25} & & & $0.3048,0.6096,0.9144$, & 5 \\
& \multirow{2}{*}{0} & \multirow{2}{*}{16} & 60 & $1.2192,1.524,1.8288$, & 15 \\
& & & $2.1336,2.4384,2.7432$ & 30 \\
\hline
\end{tabular}


From Fig. 5 (a), when $a_{\mathrm{H}}$ is positive and pointing into the slope, $l$ presents an increasing tendency with the increase in the slab thickness $d$ for both case 1 and case 2 . When $\Phi_{j}$ is constant, $l$ of case 2 is larger than $l$ of Case 1, it means that the slope remains more stable in case 2 than case 1. Because a larger $l$ need more critical driving force which means less chance for a slope to fail by buckling. In Fig. 5 (b), $l$ presents an increasing tendency with the increase in the slab thickness $d$ for both case 1 and case 2 . When $\Phi_{j}$ is constant, $l$ of case 2 is smaller than $l$ of case 1 , it means that the slope remains more stable in case 1 than case 2. When $\Phi_{j}$ is constant, $l$ of Fig. 5 (a) is bigger than $l$ of Fig. 5 (b). It means that $a_{\mathrm{H}}$ pointing into the slope favors the stability of slope.

\subsection{Analysis of the rock slope at K745}

According to the field investigations ( $\mathrm{Zhu}$ et al 2012) and the rock tests (Huang et al 2005), the mechanical properties of the slate at K745 are as follows: Young's modulus $20 \mathrm{GPa}$, friction angle $45^{\circ}-60^{\circ}$ and unit weight $25-27 \mathrm{kN} / \mathrm{m}^{3}$.

In addition, it is recorded that destructive earthquake seldom occurred during the period of $1970 \sim 2006$. The largest earthquake occurred near the Raikot bridge of KKH in November 2002. Its magnitude was M6.5 and the horizontal acceleration $a_{\mathrm{H}}=0.05 \mathrm{~g}$ (China Road and Bridge Corporation 2007). Then a horizontal acceleration $a_{\mathrm{H}}=0.05 \mathrm{~g}$ is considered in calculation and the critical slope length $l$ calculated by Eqn. (5) is $31.54-32.36 \mathrm{~m}$. The slope length in the field is $15.58 \mathrm{~m}$, which is smaller than the critical slope length. Therefore, the slope should not fail, buckling process might have involved in this slope deformation but did not reach the critical state.

On the basis of section 3.1, only the negative seismic acceleration (pointing out of slope) is considered in following analysis. For the given slope of K745, influences from three parameters are analyzed, the negative seismic force (horizontal acceleration), slope inclination angle $\alpha$ and friction angle $\Phi_{j}$ (see Table 2). The parameter values used in this case analysis are shown in Table 3 . The inclination angle to be considered is $50^{\circ}-70^{\circ}$. Meanwhile, the friction force must exist and the horizontal acceleration in the range of $0.37 \mathrm{~g} \sim 0$ is taken into account.

Case 3: with friction angle $\Phi_{j}=45^{\circ}$ and $60^{\circ}$, respectively, the critical total slope length $l$ is calculated for various inclination angle $\alpha$ and different horizontal acceleration. The results are shown in Fig. 6.

Case 4: with inclination angle $\alpha=50^{\circ}$ and $70^{\circ}$, respectively, the critical total slope length $l$ is calculated for various friction angle $\Phi_{j}$ and different horizontal acceleration. The results are presented in Fig. 7.

Table 2 Parameters from field investigation

\begin{tabular}{lc}
\hline \multicolumn{1}{c}{ Parameters } & Values \\
\hline Horizontal & $a_{\mathrm{H}}=-0.037 \mathrm{~g}$ \\
acceleration & $a_{\mathrm{H}}=-0.03 \mathrm{~g}$ \\
& $a_{\mathrm{H}}=-0.02 \mathrm{~g}$ \\
\hline Inclination angle $\alpha$ & $50^{\circ}, 60^{\circ}, 70^{\circ}$ \\
\hline Friction angle $\Phi_{j}$ & $45^{\circ}, 50^{\circ}, 55^{\circ}, 60^{\circ}$ \\
\hline
\end{tabular}

Table 3 Parameters used in case analysis

\begin{tabular}{cccc}
\hline $\begin{array}{c}\text { Friction } \\
\text { angle } \\
\Phi_{j}\end{array}$ & $\begin{array}{c}\text { Inclination } \\
\text { angle } \\
\alpha\end{array}$ & $\begin{array}{c}\text { Horizontal } \\
\text { acceleration }\end{array}$ \\
\hline Case 3 & $45^{\circ}, 60^{\circ}$ & $50^{\circ}, 60^{\circ}, 70^{\circ}$ & $\begin{array}{l}a_{\mathrm{H}}=-0.037 \mathrm{~g} \\
a_{\mathrm{H}}=-0.03 \mathrm{~g}\end{array}$ \\
\hline Case 4 $\begin{array}{r}45^{\circ}, 50^{\circ}, \\
55^{\circ}, 60^{\circ}\end{array}$ & $50^{\circ}, 70^{\circ}$ & \begin{tabular}{l}
$a_{\mathrm{H}}=-0.02 \mathrm{~g}$ \\
\hline
\end{tabular} \\
\hline
\end{tabular}

Figure 6 illustrate that at a specific horizontal acceleration, the total critical slope length $l$ decreases with the increase in inclination angle $\alpha$ but with different variation trends. For example, the variation trend of $\Phi_{j}=60^{\circ}$ is much more significant than the trend of $\Phi_{j}=45^{\circ}$. When the inclination angle is same, $l$ decreases with the increase in horizontal acceleration. For example, when the inclination angle is $50^{\circ}$, the lower bound of $l$ is $38.10 \mathrm{~m}, 45.73 \mathrm{~m}$ and the upper bound of $l$ is $44.45 \mathrm{~m}, 96.75 \mathrm{~m}$. When the inclination angle is $70^{\circ}$, the lower bound of $l$ is $32.09 \mathrm{~m}$ for both $\Phi_{j}=$ $45^{\circ}, 60^{\circ}$, and the upper bound of $l$ is $34.58 \mathrm{~m}$ and $36.31 \mathrm{~m}$, respectively. The result suggests that the slope with a large inclination angle is less stable. 

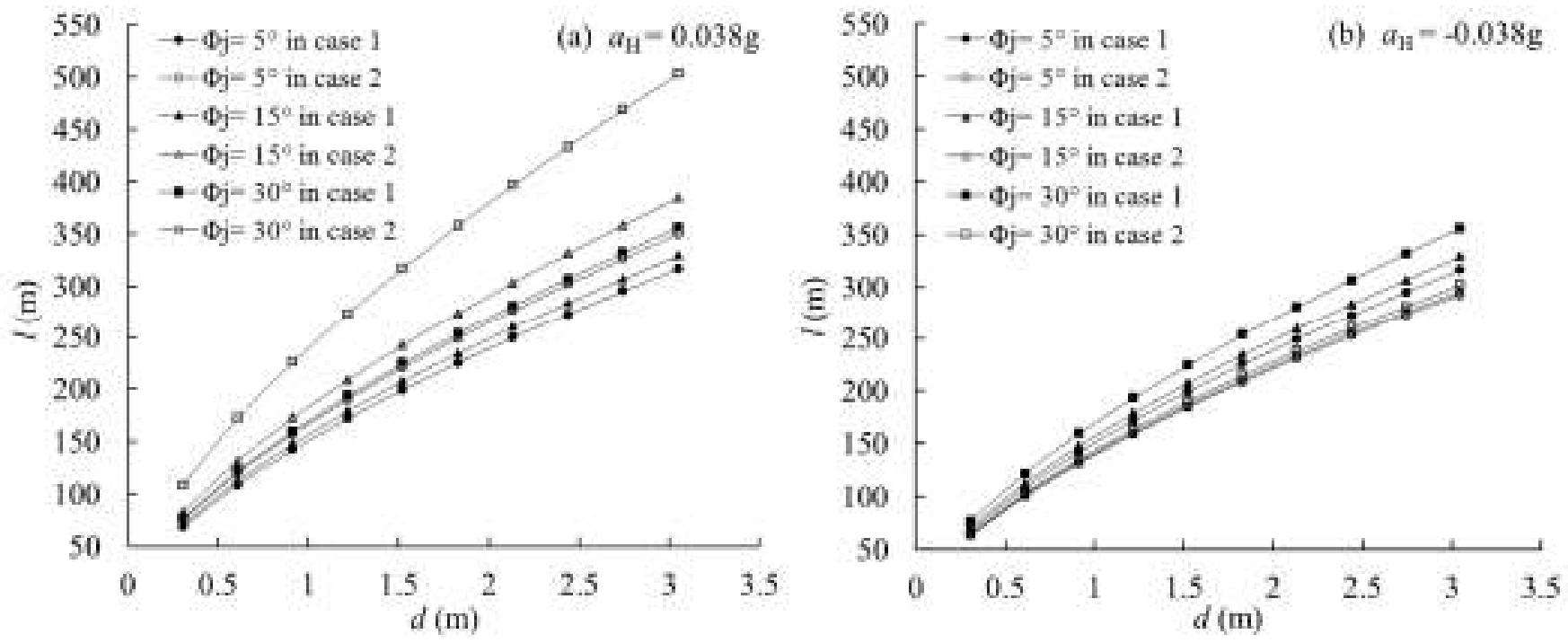

Fig. $5 l$ varies with $d$ under horizontal seismic acceleration, (a) $a_{\mathrm{H}}=0.038 \mathrm{~g}$ and (b) $a_{\mathrm{H}}=-0.038 \mathrm{~g}$
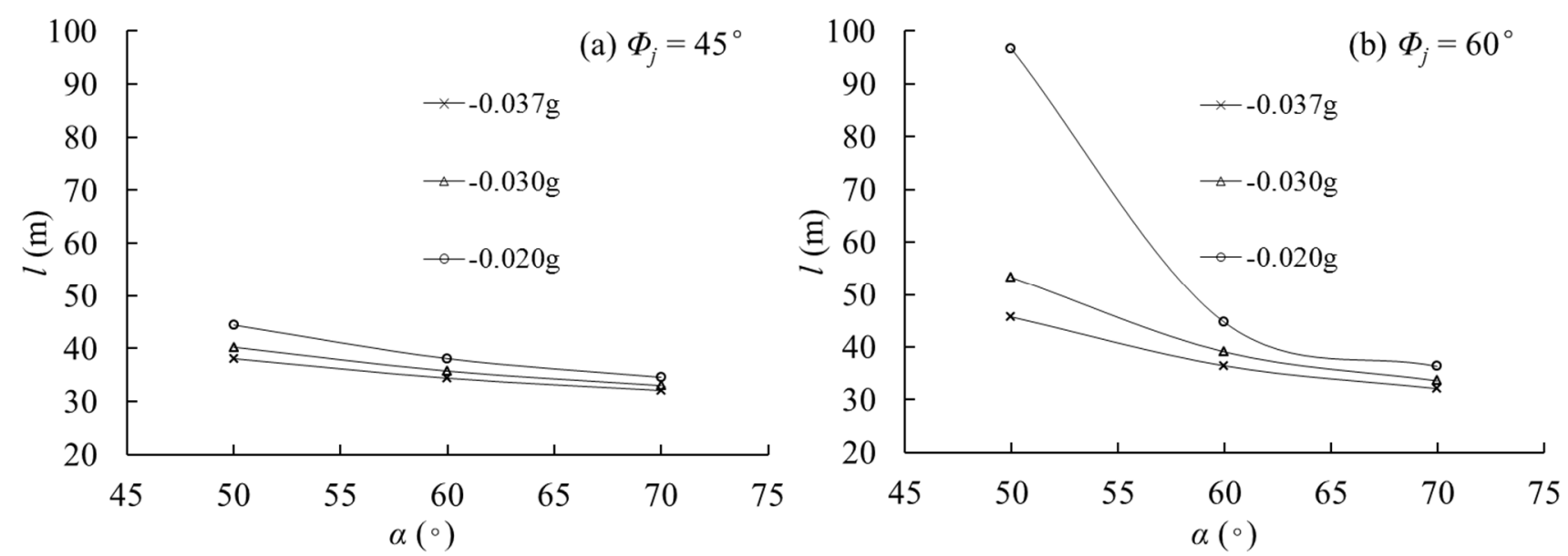

Fig. 6 Critical slope length $l$ varies with inclination angle $\alpha$ in different horizontal acceleration, (a) $\Phi_{j}=45^{\circ}$ and (b) $\Phi_{j}=60^{\circ}$
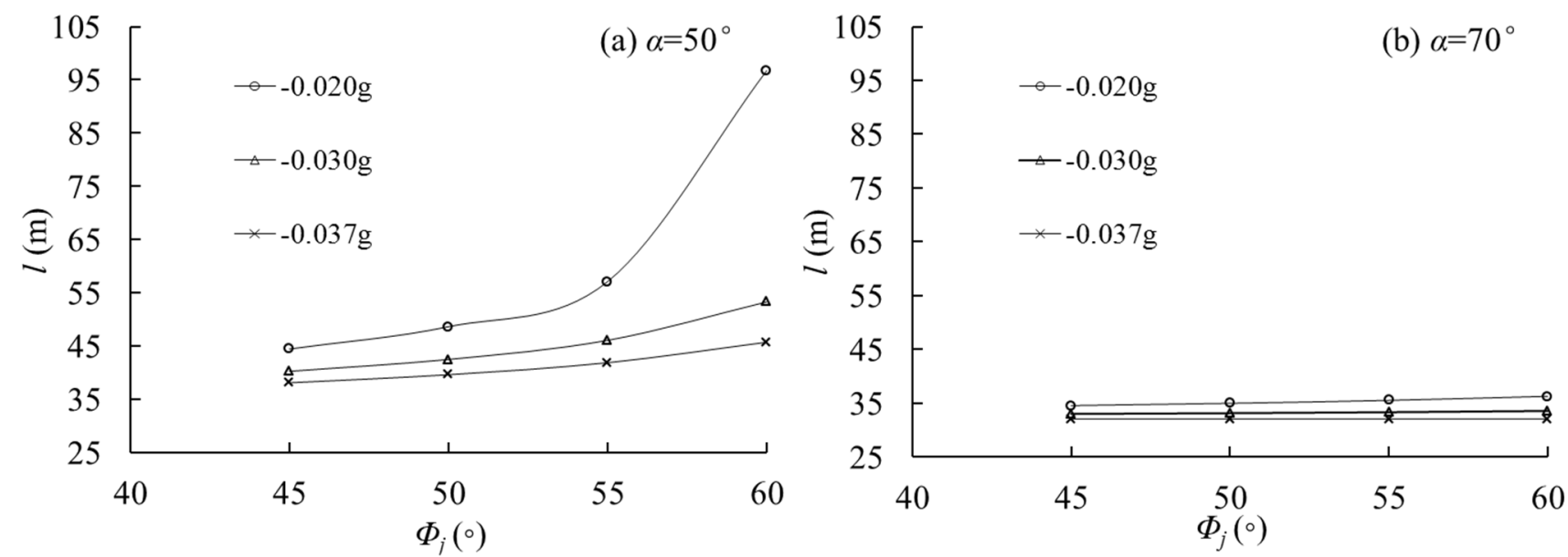

Fig. 7 Critical slope length $l$ varies with friction angle $\Phi_{j}$ in different horizontal acceleration, (a) $\alpha=50^{\circ}$ and (b) $\alpha=70^{\circ}$ 
Figure 7 illustrates that for a given horizontal acceleration, $l$ increases with the increase in friction angle $\Phi_{j}$ but with different variation trends. For example, the variation trend of $\alpha=50^{\circ}$ is much more significant than the trend of $\alpha=70^{\circ}$. A small variation of $l$ occurs when $\alpha=70^{\circ}$. If the friction angle is same, $l$ decreases with the increase in horizontal acceleration. For example, when the friction angle is $45^{\circ}$, the lower bound of $l$ is 38.11 $\mathrm{m}, 32.09 \mathrm{~m}$ and the upper bound of $l$ is $44.46 \mathrm{~m}$, $34.58 \mathrm{~m}$; when the friction angle is $60^{\circ}$, the lower bound of $l$ is $45.73 \mathrm{~m}, 32.09 \mathrm{~m}$ and the upper bound of $l$ is $96.75 \mathrm{~m}, 36.31 \mathrm{~m}$. The result suggests that a large friction angle can contribute to a high stability.

\section{Discussion}

Retrospective studies indicate that critical slope length is affected by three key parameters seismic force (horizontal acceleration), slope inclination angle and friction angle. From the stability point of view, a horizontal acceleration pointing into slope leads to increase of friction force, which favors the stability of slope. If the sum of friction force and seismic force $F_{e x}$ exceeds the tangential component of gravity, the driving force becomes negative. There is no buckling problem.

On the contrary, a horizontal acceleration pointing out of slope leads to increase of driving force and means higher possibility of failure. In this case, if a seismic force $F_{e y}$ exceeds the normal component of gravity (normal pressure), the friction force will be reduced to zero or become negative. At that moment, the driving segment may not be in contact with the underneath strata and the seismic force $F_{e x}$ will point down the slope. All of these will result in an increased driving force and the buckling potential becomes higher. In conclusion, a bigger negative horizontal acceleration (pointing out the slope), a larger inclination angle and a smaller friction angle will lead to a smaller critical slope length and a higher possibility of failure. The reason is that a bigger inclination angle means the bigger sliding force from the normal component of gravity, a smaller friction angle and a bigger negative acceleration lead to a smaller friction force and a bigger driving force for buckling.

\section{Conclusions}

Buckling is one type of deformation of bedded rock slope in the northern region of KKH. Seismic force in this region is an important parameter and should be taken into account in buckling failure research. In this paper, buckling of bedded rock slope subject to seismic force has been studied, involving an explicit failure formula, critical slope length characteristics with and without a seismic force, and the effects of seismic force (horizontal acceleration), slope inclination angle and friction angle on buckling failure. The following conclusions can be made from this paper: 1) Horizontal seismic acceleration with its direction pointing out of slope favors the buckling failure of slope; 2) During a buckling process, for a given seismic force and a slab thickness, a bigger slope inclination angle and a smaller friction angle lead to a higher possibility of buckling failure; and 3) Eqn. (5) is suitable for different seismic force situations, negative or positive.

\section{Acknowledgement}

This study was funded by the National Natural Science Foundation of China (NSFC no. 41071058) and Department of Land and Resources of Guangxi Zhuang Autonomous Region of the People's Republic of China (no. GXZC2015-G33917-KLZB-L, GXZC2015-G3-3917-KLZB-M).

\section{References}

Adhikary, D.P., H.B. Muhlhaus and A.V. Dyskin, 2001. A numerical study of flexural buckling of foliated rock slopes. International Journal for Numerical and Analytical Methods in Geomechanics, 25: 871 - 884. DOI: 10.1002/nag. 157

Cavers, D.S., 1981. Simple methods to analyze buckling of rock slopes. Rock Mechanics, 14: $87-104$.

Chajes, A., 1974. Principles of Structural Stability Theory. Civil Eng. and Eng. Mech. Series. Englewood Cliffs, New Jersey: Prentice Hall. 
Corbyn, J.A., 1978. Stress distribution in laminar rock during sliding failure. International Journal of Rock Mechanics and Mining Sciences \& Geomechanics, 15: 113 - 119.

China Road and Bridge Corporation, 2007. The general direction of engineering geological investigation on Pakistan Karakorum Highway (Raikot-Khunjerab)

Froldi, P. and P. Lunardi, 1995. Buckling failure phenomena and their analysis. Proceedings on the Second International Conference on the Mechanics of Jointed and Faulted Rock. Balkema, Rotterdam: 595 - 603.

Goodman, R.E., 1976. Methods of Geological Engineering in Discontinuous Rocks. San Francisco: West Publishing.

Hoek, E. and J. Bray, 1981. Rock Slope Engineering (Revised third edition). The Institution of Mining and Mellurgy, London.

Huang, X.C., L.J. Tao and W.G. Cao, 2005. Rock mechanics. Higher Education Press, Beijing, China.

Kutter, H.K., 1974. Mechanisms of slope failure other than pure sliding. In: MuÈ 1ler, L. (ed.) Rock mechanics. CISM Courses and Lectures 165. Springer, Wien-New York.

Li, H.B., K.Q. Xiao and Y.Q. Liu, 2007. Factor of safety analysis of bedding rock slope under seismic load (in Chinese). Chines Journal of
Rock Mechanics and Engineering 26: 2385 2394.

Li, W.G. and J.C. Zhang, 2007. Equivalent static stability study on rock mass bedding slope under blasting (in Chinese). Journal of Mountain Science, 25: 184 - 189.

Liu, X.L. and D.P. Zhou, 2002. Stability analysis of layered dip rocky slopes with elastic plane theory (in Chinese). Rock and Soil Mechanics, 23: 162 - 165.

Pant, S.R. and D.P. Adhikary, 1999. Implicit and explicit modelling of flexural buckling of foliated rock slopes. Rock Mech. Rock Engng, 32: 157 - 164.

Pereira, L.C. and M.S. Lana, 2013. Stress-strain analysis of buckling failure in phyllite slopes. Geotech Geol Eng, 31: 297 - 314. DOI 10.1007/s10706-012-9556-8

Shou, K.J. and C.F. Wang, 2003. Analysis of the Chiufengershan landslide triggered by the 1999 Chi-Chi earthquake in Taiwan. Engineering Geology, 68: 237 - 250.

Zhu, Y.Y., Y.Y. Wang, J.D. Chen, Z.Q. Yang and L.P. Liao, 2012. Report of the Key technology of environmental protection and controlling of geohazrd along China-Pakistan Karakorum Highway. 